Jörg Menzel

\title{
Internationales Öffentliches Recht
}

Verfassungs- und Verwaltungsgrenzrecht in Zeiten offener Staatlichkeit

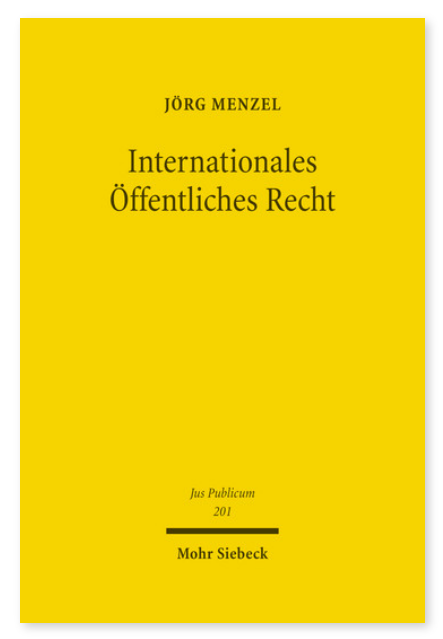

2011. XIV, 974 Seiten. JusPubl 201

ISBN 978-3-16-151282-7

DOI 10.1628/978-3-16-151282-7

eBook PDF 189,00€
Jedes Rechtsgebiet hat sein Grenzrecht. Ein Internationales Öffentliches Recht (mit den Teilgebieten Internationales Verfassungsrecht und Internationales Verwaltungsrecht) ist genauso erforderlich wie ein Internationales Privatrecht oder ein Internationales Strafrecht. Deutsches Öffentliches Recht muss die Frage seines Wirkungskreises definieren und es muss klären, in welchem Umfang ausländisches öffentliches Recht im eigenen Wirkbereich zugelassen wird.

Jörg Menzel erarbeitet die Grundlagen und Themen eines Internationalen Öffentlichen Rechts und liefert damit die erste Gesamtdarstellung auf diesem Gebiet. Er widmet sich nach ausführlicher Grundlegung den überstaatlichen (völker- und europarechtlichen) Vorgaben und sodann im Einzelnen dem deutschen Internationalen Verfassungs- und Verwaltungsrecht. Hierbei verfolgt er einen Ansatz, der auf dem Prinzip des offenen Staates und der daraus resultierenden grundsätzlich positiven Grundeinstellung der Rechtsordnungen zueinander beruht, die auch das öffentliche Recht nicht ausspart. Der Autor zeigt auf, dass Internationales Privatrecht und Internationales Öffentliches Recht weniger gegensätzlich sind als häufig kolportiert, weil die innen zugrunde liegenden Grundgedanken nicht verschieden sind. Er geht den Strukturen eines Internationalen Öffentlichen Rechts ebenso nach wie vielfältigen Details und weist nach, dass es im Öffentlichen Recht Prinzipien zu diskutieren gibt - auch wenn dort die Strukturen zum Teil anders sind als im IPR.

Jörg Menzel (1965-2016) war zuletzt Professor an der Türkisch-Deutschen Universität in Istanbul.

Jetzt bestellen:

https://mohrsiebeck.com/buch/internationales-oeffentliches-recht-9783161512827?no_cache=1

order@mohrsiebeck.com

Telefon: +49 (0)7071-923-17

Telefax: $+49(0) 7071-51104$ 